\title{
QUEEN'S
UNIVERSITY
BELFAST
}

\section{Belonging and the inter-generational transmission of place identity: reflections on a British inner-city neighbourhood}

Frost, D., \& Catney, G. (2020). Belonging and the inter-generational transmission of place identity: reflections on a British inner-city neighbourhood. Urban Studies, 57(14), 2833-2849.

https://doi.org/10.1177/0042098019887922

Published in:

Urban Studies

Document Version:

Peer reviewed version

Queen's University Belfast - Research Portal:

Link to publication record in Queen's University Belfast Research Portal

Publisher rights

Copyright 2019 Sage. This work is made available online in accordance with the publisher's policies. Please refer to any applicable terms of use of the publisher.

\section{General rights}

Copyright for the publications made accessible via the Queen's University Belfast Research Portal is retained by the author(s) and / or other copyright owners and it is a condition of accessing these publications that users recognise and abide by the legal requirements associated with these rights.

Take down policy

The Research Portal is Queen's institutional repository that provides access to Queen's research output. Every effort has been made to ensure that content in the Research Portal does not infringe any person's rights, or applicable UK laws. If you discover content in the Research Portal that you believe breaches copyright or violates any law, please contact openaccess@qub.ac.uk. 


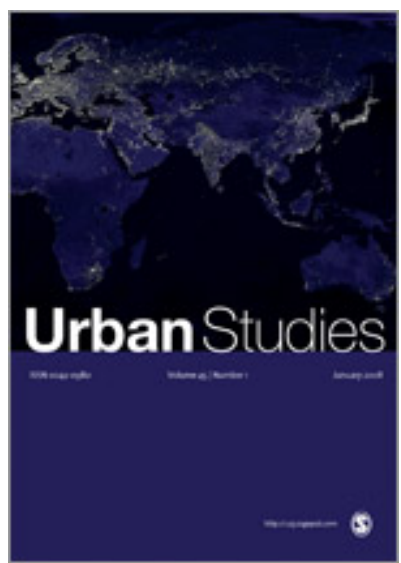

\section{Belonging and the inter-generational transmission of place identity: reflections on a British inner-city neighbourhood}

\begin{tabular}{|r|l|}
\hline Journal: & Urban Studies \\
\hline Manuscript ID & CUS-660-19-07.R1 \\
\hline Manuscript Type: & Article \\
\hline $\begin{array}{r}\text { <b>Discipline: Please select a } \\
\text { keyword from the following } \\
\text { list that best describes the } \\
\text { discipline used in your paper.: }\end{array}$ & Sociology \\
\hline $\begin{array}{r}\text { World Region: Please select } \\
\text { the region(s) that best reflect } \\
\text { the focus of your paper. }\end{array}$ & \\
$\begin{array}{r}\text { Names of individual countries, } \\
\text { cities \& economic groupings } \\
\text { should appear in the title } \\
\text { where appropriate.: }\end{array}$ & Western Europe \\
\hline $\begin{array}{r}\text { Major Topic: Please identify } \\
\text { up to } 5 \text { topics that best } \\
\text { identify the subject of your } \\
\text { article.: }\end{array}$ & Community, History/heritage/memory, Inequality, Neighbourhood, \\
\hline $\begin{array}{r}\text { You may add up to } 2 \text { further } \\
\text { relevant keywords of your } \\
\text { choosing below:: }\end{array}$ & Class, inner-city \\
\hline
\end{tabular}

\section{SCHOLARONE \\ Manuscripts}




\title{
Belonging and the inter-generational transmission of place identity: reflections on a British inner-city neighbourhood
}

\begin{abstract}
This paper explores the subjectivities of neighbourhood identity and belonging. It considers how far, and in what ways, place identity and attachment are transmitted cross-generationally. Three broad themes have framed this research. Firstly, the ways in which the formation and reproduction of neighbourhood identities have been influenced by geographical, political, contemporary and historical contexts. Secondly, and relatedly, the roles played by intersectional factors such as race and class. Thirdly, the extent to which alternative neighbourhood identities challenge and contest 'mainstream' narratives that stigmatise and undermine disadvantaged inner-city communities. This paper draws on a case study area of 'Liverpool 8' (part of the wider Toxteth locale), a historically ethnically diverse inner-city area which attracted negative press coverage during the 1980s and 2011 riots. Drawing on a series of in-depth interviews with residents, the research reveals evidence of strong neighbourhood belonging and identity, shared and diffused across generations, based on subjective experiences, both positive (e.g., celebration of diversity, neighbourliness), and negative (e.g., racism, discrimination). To some extent, younger generation narratives reveal subtle changes that suggest a broadening of spatial horizons, beyond residents' immediate neighbourhood. However, at the same time, socio-economic and ethnic inequalities act to temper and stifle socio-spatial networks and experiences outside the immediate neighbourhood, for younger as well as older - generations.
\end{abstract}

Keywords Generation, belonging, identity, neighbourhood, inner-city

\section{Introduction and academic context}

Recent contributions to debates around belonging have deepened our understandings of attachment to place by encouraging the need to explore a multiplicity of belongings, including the inter-relationships between different 'scales of belonging' (Antonsich, 2010; May 2011; May and Muir, 2015: 2; Wood and Waite 2011). It has been demonstrated that everyday interactions and relationships can reveal contradictory displays of 'conflict as well as 
conviviality'; of complex 'ambivalences' that challenge unidimensional descriptions of community and belonging (Karner and Parker, 2011: 366). Using a micro-empirical study of neighbourhood in Liverpool 8, an ethnically diverse working-class inner-city neighbourhood, this paper examines cross-generational attachments to neighbourhood. It explores narratives and experiences around racism, safety, activism and policing, particularly past experiences of older generations, and explores whether these impact upon the spatial horizons of resident younger generations. In doing so, the paper considers the continuities of experiences across generations, as well as changes, situating these in wider societal and global forces.

The originality of this work rests on exploring community belonging across generations, to understand how this intersects with place, neighbourhood, class and 'race', and whether there are qualitative differences between younger and older generations. It contributes to existing research on neighbourhood and generation by highlighting the significance of locality to intergenerational experiences of age (Hopkins and Pain, 2007). In exploring intergenerational changes around belonging, this assumes an understanding of community that links to imaginaries, place and materiality. The research is less concerned with notions of 'performing community' (Blokland, 2017), but seeks instead to understand how young people balance the contradictions and constraints from several quarters: firstly, the way neighbourhood narratives are passed down from older generations, particularly around neighbourhood boundaries and mobility that relate to racial hostility and safety. Secondly, the way young peoples' attachment to locality can be enforced through socio-economic restrictions placed on those from disadvantaged neighbourhoods. This is particularly pertinent given how British austerity policies since 2010 disproportionately impact the most deprived neighbourhoods (Meegan et al., 2014). Both processes - the intergenerational transmission of belonging and identity, and the impact of inequalities - potentially have a stifling impact on some young people that leads to a greater pull towards locality. At the same time, and thirdly, such restraints must be managed against the demands and expectations arising from narratives that champion globalisation (as against parochial locality) and the apparent greater opportunities for mobility this brings (Harris, 2014). Grappling with these issues, demands an exploration of how young people both perceive and engage with belonging to neighbourhood.

Related is the growing body of research on studies that show how class identities can impact experiences of neighbourhood. Case studies have demonstrated how articulations of class manifest themselves differently (Jackson and Benson, 2014; Savage, 2005), though 
neighbourhood and locality appear to be more salient amongst working-class residents (Watt, 2006). However, this can vary across neighbourhoods in the same town or city, pointing to the significance of micro neighbourhood-specific contexts. Thus, levels of neighbourhood attachment can be contingent on historical and local developments (Cole, 2013). This resonates strongly with the present study of Liverpool 8, where, as is discussed later, historical specificity and development continues to impact on local and contemporary understandings of belonging to neighbourhood.

Changes in the way neighbourhood identity and belonging are articulated have been positioned in broader social and political processes associated with globalisation that impact locally on the way social connections across familial and friendship networks operate. It has been shown that as social life becomes more spatially-dispersed through technologies of social and communication media which traverse place-based allegiance, the effect is to loosen ties to neighbourhood and place. This is particularly salient for younger generations (Cass et al., 2005; Savage et al., 2005 cited in Warr, 2015). Yet for disadvantaged young people, spatial horizons continue to be bounded and wedded to locality. Warr (2015) for example, highlights how inequalities linked to economic marginalisation and poverty can strengthen local relationships with family and friends, and thus militate against processes of detachment to neighbourhood. Moreover, additional strains of place stigmatisation and racial discrimination experienced outside the immediate neighbourhood reinforce social disconnections, whilst simultaneously enhancing neighbourhood as a spatially and socially significant place of support, belonging and attachment (Warr, 2015). Therefore, while concepts of community and neighbourhood belonging depend on imaginaries, or 'being in common' (Jackson and Benson 2014; Neal et al., 2018; Studdart and Walkerdine 2016), at the same time, neighbourhood identity cannot be divorced from wider concerns around power, inequality, exclusion and privilege (Putnam, 2000). 'Place' construction, then, is both reflective of societal ideas, whilst also being influenced by the socio-economic and physical materiality of society (Massey, 1995).

In Liverpool 8, historical experiences of racism, stigma and economic marginalisation, alongside community activism (Frost, 2013), have reinforced attachment and identity as an overtly political identity, particularly amongst older generations. This research explores how specific 'moments' like the so-called 'riots', alongside more 'everyday' tensions, around racial policing, stereotyping, and exclusion - both collective and shared - shape allegiances to place for those who have experienced them 'firsthand', and are diffused to successive generations. 
Just as memory can play a crucial role in developing attachment to place (as Rishbeth and Powell, 2012, explore for migrants to Sheffield; see also Hoelscher and Alderman, 2006, for a review of the relationship between memory and place), the intergenerational communication of memory can have a significant role in shaping political formations (Mitchell and Elwood, 2013). This paper thus aims to understand the role of the intergenerational transmission of memory to subsequent generations in influencing place identity, neighbourhood attachment, and young people's socio-spatial horizons.

The paper develops original and innovative areas of enquiry around the intergenerational transmission of neighbourhood belonging and place identity, by: strengthening our knowledge of social change across generation, capturing the developing and dynamic nature of diverse working-class neighbourhoods, and highlighting the relevance of micro local empirical studies and their relationship to wider concerns around 'race' and class. This work derives from a broader British Academy funded project on The Role of People and Place in Neighbourhood Identity: Belonging and Social Inclusion that explores the inter-relationships between neighbourhood belonging, identity and community in south Liverpool.

\section{Liverpool 8: the impact of history}

The postcoded area of 'L8' or Liverpool 8 (used interchangeably with 'Toxteth') offers what Gilroy (1987) and others label 'symbolic location' in terms of the distinctiveness of the area based on historical events, 'charged meanings', or 'political and cultural associations' (Neal et al., 2016: 497). The postcode L8 was initially used to describe a police beat in the 1970s (Murphy, 2011). Its use since then by those inside and outside its boundaries to define this ethnically diverse neighbourhood is particularly notable, and indeed distinctive, in the wider city context. Liverpool 8 has historically been home to concentrated minority Black settlement, long before the mass migrations of the 1950s and 1960s, and enhanced by its high rates of historical inter-racial mixing (Frost, 2008; Christian, 1995; Costello, 2001; Small, 1991; Tabili, 1996). It composes two wards: Princess Park and Riverside which, according to the 2011 Census, were home to Black, Asian and Minority Ethnic (BAME) populations of 51.2 per cent and 20.4 per cent respectively (Liverpool City Council, 2015). Both wards are home to longstanding Black and White British working-class residents, as well as recent immigrant groups. The area became the scene of urban unrest in the 1980s and in 2011. Parts of Liverpool 8 are also being gentrified, as professionals and others are purchasing period properties in the now sought after 'Georgian Quarter'. In 2015, the area attracted more positive media attention when 
it won the Turner Prize for its community regeneration project 'Granby Four Streets' (Foster, 2015). Whilst not the poorest area in Liverpool, its two wards constitute two of the most deprived, according to the Index of Multiple Deprivation (Liverpool City Council, 2015).

Historical processes steering BAME groups to a bounded geographical area - Liverpool 8 (Frost 1996), dating back to before the Windrush generation of the 1950s and 1960s, went hand-in-hand with exclusion from other areas of the city. Such spatial confinement was augmented and policed by widespread experiences of racial abuse (verbal and physical assault) from areas outside the neighbourhood. It is only in recent years that BAME groups, mainly refugees and asylum seekers, have begun to disrupt these historical and entrenched settlement patterns through enforced, managed migration settlement beyond Liverpool 8. Shirlow's (2003) work on ethno-sectarian and political violence in Northern Ireland demonstrates well the complexities of fearfulness and how this has resulted in self-imposed spatial restrictions for some communities, based on constructions of knowledge around 'safe' and 'unsafe' areas. Whilst the social, political and historical context of Liverpool is markedly different from Northern Ireland, there are echoes that resonate. Testimonies in Liverpool, as we shall see, point to cross-generational knowledge and experience relating to historical spatial circumscription and enforced self-confinement to the safety of one's neighbourhood. Painful and traumatic experiences have forged a tenacious sense of attachment to Liverpool 8 , particularly amongst the older generations (Catney et al 2018). Long after this spatial concentration has been diluted (with the growth of Black communities outside Liverpool 8), there continues to be 'no-go' (sic) areas in Liverpool, where Black people, both young and old, will avoid venturing, for fear of racism.

\section{Methodology}

We use in-depth semi-structured interviews to explore several inter-related factors involved in the complexities of neighbourhood attachment and identity. Interviews were conducted with 16 local residents over an 18-month fieldwork period. Interviews lasted for up to an hour, drawn from a mix of genders ${ }^{1}$, age groups and self-identified ethnic backgrounds. This purposeful sample included long-standing residents, recent newcomers and those who, despite moving away, retained an affinity with the area. Given the relatively small sample size, generations are defined intentionally broadly as 'younger' (30-39 and below; $n=6)$ and 'older' (40-49 and above; $\mathrm{n}=10$ ). Thematic analysis based on coding (for example: safety, belonging, racism, generation, mobility) of transcribed interview text was used to map the data against 
conceptual and theoretical questions. Whilst our sample cannot claim to be representative, rather our aim is to explore some of the experiences of those with a connection to the area, in relation to several particular themes. We draw on testimonies gathered from residents to consider the extent to which, firstly, a sense of history has been transmitted across generations. Secondly, whether such historical experiences and narratives influence younger people's feelings of attachment with Liverpool 8. Thirdly, whether the latter has influenced their spatial horizons in terms of mobility outside Liverpool 8, and indeed the wider city. Answers to such questions will be informed by broader contextual factors relating to socio-economic structures and (un)opportunities. In considering the relationships that exist between place, community and belonging, and their salience on neighbourhood identities, the 'voices' of communities themselves have an important role to play, particularly in the context of urban social policy. Utilising Frost's long-standing association with the area and its residents helped with the sampling. In using residents' narratives, we are purposively attaching value and meaning to individual and neighbourhood experiences whilst consider a wider structural context to position and highlight the importance of these. Some participants also undertook a mental mapping exercise as a means of understanding place as imagined, lived and reproduced (Lynch, 1960). This method, the results of which are reported elsewhere (see Catney et al, 2018), encouraged a more participatory approach to the research, and formed part of the interview process, enabling the integration of personal experiences and perspectives, and their influence on how the area is defined and understood.

Powerful and all-consuming discourses that have pathologised, labelled and stigmatised neighbourhoods as deviant and 'threatening' (Butler, 2019; Devereux et al., 2011), particularly by those in positions of power and authority (McKenzie, 2015; Wacquant 2007), can have a destructive impact on individuals and communities, causing even greater social exclusion, marginalisation and discrimination. Such processes attempt to silence or distort alternative and marginal narratives, so that the task of making more visible such voices continues to remain a challenge. They also aid in rendering these communities 'unimportant', 'problematic', and thus voiceless. Similarly, marginal communities have been largely absent in processes and developments around urban planning and policy. Initiatives encouraging participation have been problematised (Harvey, 2008: 32). Thus, regeneration developments in 1980s and 1990s Liverpool resulted in 'no sense of a real engagement with communities, either through existing structures of representation or in new arrangements, even though that would have been claimed...' (Rooney, 2003: 218). 
We have simultaneously seen an increasing number of studies centred on documenting the experiences of, and voices within, diverse marginal communities. This study on Liverpool adds to these burgeoning studies by highlighting a geographically distinct micro-study of neighbourhood that is both unique and universal in terms of its findings. Contextualising Liverpool 8 (within its unique socio-historical and political framework) with the inclusion of previously unheard neighbourhood voices, can aid in establishing a more meaningful understanding of 'mainstream' narratives and discourse. Grassroot voices add an important local empirical study to existing ones. In doing so, this increases the voices of those that offer alternative and 'authentic' narratives that serve to enrich and enhance the material gathered, and significantly challenge 'some of the assumptions and accepted judgments...' (Thompson, 2000: 29; Rogaly and Taylor, 2009; Butler, 2019).

\section{Findings across the generations}

Our analyses found that the importance of place runs through several inter-linked themes which are inclusive of physical and perceptual characteristics, as well as social relationships, that can be: 'politicized, culturally relative, historically specific, local and multiple constructions' (Rodman, 1992:641 cited in May and Muir, 2015: 4). A co-existence of multiple forms of belongings was noted. Some of these were common across generations, others were inherited or passed down from older generations, and some reflected different generational experiences. 
As with allied studies on disadvantaged communities (see McKenzie, 2015; Slater and Anderson, 2012; Wacquant, 2008), Liverpool 8 residents have battled with negative portrayals of their community in mainstream discourses. Alternative narratives from interviews with residents emphasised belonging as rooted in a history and culture around diversity and local struggles that imbued a strong sense of pride of place. Such views not only challenge and resist negative stereotypes, but are the very characteristics that have created strong social bonds here. A sentiment articulated across generational groups was 'belonging through discrimination', particularly the ways in which neighbourhood stigma impacts on residents. One respondent commented: 'People used to say “don't go into the 8"' (40-49, male, Black), and another: '[...] because Liverpool 8 is [...] Black and it's Toxteth, it's been labelled and it's very difficult to get rid of that' (50-59, female, Pakistani, Muslim). This latter respondent also discussed how the postcode of Liverpool 8 is associated with certain barriers:

Personally, I've experienced trying to get insurance for the shop and it has been a nightmare $[\ldots]$ because of the riots and what's happened over the years, [...] insurances for property and cars, access to education and housing, because it's Liverpool 8 and its Toxteth and the stereotyping around that area, [...] (50-59, female, Pakistani, Muslim).

Negative images around crime and safety continue to be held by some younger people outside of Liverpool 8: 'that stigma is still there, oh yes, very much so, especially with young people I work with. They associate a lot of the violence with Toxteth [...] if they are travelling through Toxteth they will carry knives, [...] they've heard bad things about the place (40-49, female, Black Mixed heritage). Across generations, many residents challenged such views by emphasising safety in L8 compared to other areas of the city: '[...] I get very defensive about the place because I've lived there a long time now and I'd say it's one of the safest places I've ever lived in Liverpool' (40-49, female, Black Mixed heritage). Others commented: 'I always felt safe, we moved to L15 and got robbed' (30-39, female, Black Nigerian); '[...] it was more than just a postcode [...], well, it's just got more warmth to it. I feel totally safe there. I can be myself' (60-69, female, Mixed heritage Jewish and Chinese); 'it was like a security blanket, that's where you go to be safe' (30-39, female, Black Nigerian), and with reference to violence: 'I feel safe, I've got no fear. No fear of people with knives, guns, nothing. But I'd be scared more so outside of my Liverpool 8 of guns and knives [...]' (50-59, male, Black Mixed heritage). 
Yet despite these positive accounts, residents' discussions about safety outside of Liverpool 8, relating to either direct experiences or fear of racial attack, were prevalent. Articulations of racism and safety were in turn interspersed with narratives around socially-constructed boundaries, acceptance and diversity. Some of these social boundaries, based on negative experiences, have been passed down generationally, while others are based on first-hand experiences: 'People would tell me you can't go past Windsor Street and I'd be like, why? cos you will get your head stoved in, get beat up. Why? cos you're Black. I couldn't go down Mill Street where I went to school, I couldn't go into town [...] I couldn't go past Wavertree' (4049, male, Black) Another explains:

[name of school]: that is probably classed as L8 [Dingle Lane]. I would never have classed that school as L8, was horrible, rough. We were the only Black kids [...]. We got so much racism. Imagine being like 6 , being called a $\mathrm{n}^{* * * * *}$, a $\mathrm{c}^{* * *}$, a $\mathrm{P}^{* * *}$. Not even understanding what these words were. [Mum] took us out because of the racism. (30-39, female, Black Nigerian).

Feelings and imaginaries around safety and boundaries, that might include postcode labels, were often passed on to younger generations:

I was very mindful when my kids started applying for jobs. I did say about changing their address to their Nan's postcode, which is Liverpool 6, cos if they see a Liverpool 8 postcode they start associating that with negative connotations. [...] when I was younger [...] a lot of people from Toxteth just weren't getting any jobs, [because of] the L8 postcode... (40-49, female, Black Mixed heritage).

Boundaries are social constructions in the imaginaries of those who reside or have connections with place (Jackson and Benson, 2014). These do not always mirror 'official' ward or postcode boundaries, and in the context of Liverpool 8, represent protective frontiers in response to painful experiences of racism, and fears around safety. Living in an ethnically diverse area has instilled safety and accentuated feelings of acceptance, including for White people: 'I just feel safe and secure in that area, [...] anything goes no matter who or whatever your identity, there's a place for you there [...]' (40-49, male, White). For one woman, growing up in the Dingle (a White working-class area), she gravitated to Liverpool 8: 
My friends were all based there, $[\ldots]$ because there was a community that didn't judge me and $[\ldots]$ encouraged me to be me; .... I was seeing people from mixed race families who looked like me [...] I didn't feel like I was the only one, it was great (50-59, female, Mixed heritage Irish and Chinese).

Another commented: 'I definitely feel part of the Liverpool 8 community [...] to just be somewhere where you could be and not have to explain who you was, what you was. Why you was what you was!' (40-49, female, Black Mixed heritage). Another respondent explains: 'For me L8 is where Black people lived [...]: you could buy African and Caribbean food [...] coming as migrants, this was where we were told to move to [...]' (30-39, female, Black Nigerian). Some accounts reflected feelings of belonging to the neighbourhood rather than the city of Liverpool: 'I don't feel part of this city. I'm part of L8 but not part of the city [...] I feel like I fit in, except when I go to town [...] there are no Black people working in town.' (50-59, male, Black Mixed heritage).

Liverpool 8's sustained ethnic diversity, including the coexistence of established and emerging communities, is for many, the key to its strong neighbourhood identity. This was important across generations, from participants in their 20s: 'The basis of L8 to me is people who are all different [...], mixed race, Somalian, Nigerian or Ghanaian backgrounds or English backgrounds.' (20-29, female, Black), to participants in their 40s (and older): '...a place of many different diverse cultures; it's a melting pot of different people. With that brings lots of different things, brings different culinary tastes and expertise, a lot of family values, a lot of good people' (40-49, male, Black).

Belonging to neighbourhood for many of these respondents was not 'freely chosen' (Antonsich, 2010) and did not constitute the 'elective belonging' identified by Savage et al. (2005), reminiscent of some middle-class neighbourhoods. Rather, belonging in Liverpool 8 emerged out of class and racial inequalities, and subsequent hardships and discrimination. Such attributes became the very basis upon which strong neighbourhood identity and belonging was positioned: 'Liverpool 8 is a unique part of Britain [...] so much character and so much has gone against it in terms of poor people being [...] neglected. When you have that situation, great people come from there' (40-49, male, White). Pride of place was an important attribute that was repeated by many respondents: '[...] there's like a unique kind of enthusiasm [...] like a proudness that they come from Liverpool 8, that no one's better than you and you are as equal 
as anyone else' (50-59, female, Mixed heritage Irish and Chinese). One respondent was careful to distinguish between pride in Liverpool (that was tempered by an unpredictability of acceptance), and pride in Liverpool 8:

[pride in Liverpool?] No, for example in town, I can go out and get called a $\mathrm{n}^{* * * * *}$ or I could get called beautiful. Have a brilliant conversation. It's just a mixed bag. I'd rather be a Scouser [regional nickname] than any other city in the UK. But I'm not going to say there is anything brilliant about being a Scouser other than being from Liverpool 8 (30-39, female, Black).

Adversity, then, has strengthened pride of place and greater attachment to neighbourhood as 'home'. Such developments connect with Slater and Anderson's (2012) work on St Paul's in Bristol, and McKenzie's (2015) on the St Ann's estate in Nottingham, where neighbourhood pride and solidarity can be a response to 'external defamation' (Slater and Anderson 2012: 540). Neighbourhood belonging in L8 has assumed a more meaningful and elevated position in relation to residents' simultaneous attachments to Liverpool and the UK. Such identity attachment acts as a form of symbolic struggle (Bourdieu, 1991) in the context of neighbourhood, by challenging imposed negative labels from above that 'blemish place' through enforced 'territorial stigmatisation' (Wacquant, 2007: 67). The empirical findings from Liverpool, like those from Bristol and elsewhere, contribute to debates on how residents themselves counter harmful stigmatising narratives.

\section{Belonging, social change and generational differences}

Elements of neighbourhood belonging have been drawn from different influences and experiences based on generation, ethnicity, and length of residency. Some continuities were apparent in experiences across generations. For example, the historical legacies of oppressive neighbourhood policing were a dominant theme. A younger informant explained: 'I think the one thing I can definitely say is the police situation probably hasn't changed at all [...] I noticed the meetings after the [2011] riots, it was that the fathers of the sons who were complaining had the same complaints 20 years before' (20-29, female, Black). An older informant had similar views: 'Oh no, [the police] still look down on us' (50-59, male, Black). Another explains: 
The older generation were on the frontline really, taking all the racism and prejudice $[\ldots]$ but there are things we have had to deal with [...] to do with class as much as race. I spent time in Garston as a teenager, and the police wouldn't have treated the poor Garston kids any different to the Liverpool 8 kids, the only difference would be they couldn't call them Black b******s. But a Garston kid would get picked up, locked in the cells, given a kicking as much as a Liverpool 8 kid. The only difference was not calling one a $\mathrm{n}^{* * * * *}(30-39$, female, Black).

Younger generations make clear distinctions in terms of the way Liverpool 8 identity was much more politicised amongst the older generation:

I think $[\ldots]$ older generations had it a lot harder than us, $[\ldots]$ they were the rioters and stuff, they have a [politicised identity with L8] a lot stronger [...] younger people don't see activism and rioting or protesting in the same way. [...] the older generations seem a lot more passionate, $[\ldots]$ have a stronger idea or vision of what Toxteth is or it should be $[\ldots]$ (20-29, female, Black).

These narratives reveal how such politicised history and its legacy is not only understood by younger generations as important, but also how this is distinct from their own experiences. There was also some recognition amongst younger groups of the way the area's stigma is changing: 'well it's not like the old days when I was a kid and say you'd go to Brighton Beach [Wirral] and you are playing with other kids, where you from - Toxteth - aaah, sharp intake of breath. I don't get that reaction anymore!' (20-29, female, Black).

Changes across generations can also be gauged in terms of the subtle ways respondents negotiate space. Younger people's spatial horizons appeared to be wider, going beyond the confines of immediate community and neighbourhood. Whilst belonging to neighbourhood can be passed down generationally, there are additional broader social and political factors that come into play which impact and influence strength and degrees of belonging. The increasing importance of social media networks beyond immediate community is particularly germane with reference to younger generations. Likewise, young people tended to have more activity spaces outside the neighbourhood, which widen not just their physical horizons, but their socioperceptual boundaries. Working, studying and socialising outside of the Liverpool 8 area was an important part of some young people's experiences, often whilst retaining social links with 
Liverpool 8. One young man, for example, worked in the city centre and had a wider geographical perception of 'his' Liverpool 8 because of his broader connections through work and social circles. This was supported by two other 'younger generation' residents: 'I don't venture more than my area south-central sort of thing. I shop [and work] in town, [...]' (30-39, female, Black).

[I visit town] more or less 5 days a week. Town to me is an extension of where I'm from [...] where I live, [...], University, work, meeting up on nights out, meeting friends, going for food. It's a big part of my life, definitely [...], I would say town and Toxteth are my main areas $[\ldots](20-29$, female, Black).

Reference was made by several respondents to the perceived greater spatial mobility of younger generations today compared to older generations. 'A lot of people who I knew growing up have moved on, but the older people are still there' (30-39, female, Black):

I think it's a Liverpool thing to think you have to leave the city to get on [...] there is that thing about you don't see Black people working in town, etc [...] A lot of people are worried about the racism. How difficult it is to get on and a lot of people move on because of that (20-29, female, Black).

A lot of the young ones have left, gone to uni outside of Liverpool. They don't want to stay $[. .$.$] but there are people who I grew up with who are still there [...]. Some friends$ have left completely, [...] in America, London, Leeds, Birmingham (30-39, female, Black Nigerian).

However, wider spatial-social boundaries within Liverpool were tempered by caution:

There are places I still wouldn't go to [...] places in Liverpool [...] I just wouldn't feel comfortable to be there as a Black person [...] Croxteth, [...] Huyton. When I hear Black [people] say they live in places like that, my instant reaction is: why?... it's still got massive barriers to overcome for me personally but [...] it is very different to what it used to be... (20-29, female, Black). 
I love being Scouse. I'm not really comfortable in all parts of the city though, [but with work] I have to go to different parts of the city. But before [...] you would never catch me in Huyton or Fazakerley or Mossley Hill. I was always around here, [...] [with] this job I go to places and I spot the odd Black face and I think, oh my God, who housed you here? Why would they do that? (30-39, female, Black Nigerian).

Another young respondent harboured different concerns:

I work in a bar [in town] so I'm there like 2 or 3 times a week, I shop [...] go to town with my mates on the weekend [ ...]. To be honest I only go where I have to cos my family or friends are there, so like Woolton, Wavertree, Allerton, Garston, Aigburth. Other than that [...] I probably wouldn't [go to] Norris Green and them ways, they sound like proper gun lands (18-29, male, Mixed heritage).

A young man who had been subject to racial abuse was less worried about travelling to different parts of Liverpool through work:

It has never put me off going into all the other areas though, out of all my friends I'm probably the most travelled around Liverpool [...] My Mum would be like 'be careful' [...]. I think when I go to North Liverpool or Halton or the Wirral [...] I'm waiting and expecting for something to happen because those areas aren't as diverse [...]. I was on the train in Prescot [...] and [was told to] 'f*** off you $\mathrm{n}^{* * * * * 1}$. [..] it's one of those areas I would expect it to happen. So, no I'm not scared of going to new areas (20-29, male, Black Mixed heritage).

Younger peoples' spatial horizons continued to be constrained by their experiences or fear of racism. Warr (2015) has argued that socio-economic marginalisation, made worse by place stigma and racism, can lead young people to have greater dependency on local networks and neighbourhood. Whilst our sample is too small to draw any significant conclusions from this, younger generations appeared to be more likely to frequent the city centre and other areas outside L8 that older generations would perhaps avoid, whilst still being constrained by clear 'no go' areas for a variety of reasons, including safety. This also relates to preferences around areas to live: 
'Yes, I feel comfortable in town and city centre [...] My Mum, she doesn't go to town. There's no reason for her to go to town [...] other people that I know are just in their little bubble [...] and that's their Liverpool, whereas my Liverpool is a lot bigger than that I think (20-29, male, Black Mixed heritage).

I wouldn't live in any majority White area. [...] I wouldn't move far out of Toxteth. [...], to Garston, Kirkby, Speke - never. I'd live in Wavertree. I've got a son going to be a teenager soon and I'm not having him where someone will call him out for stuff he doesn't need to be called out for (30-39, female, Black).

If I had the money, I'd probably still buy around the L8 area [...] never will you see me buy a house down Park Road - Dingle is where I've had the worst experience of racism in my life. You still hardly see Black faces. I could not put my child in that situation. So, I'm limited in where I would choose to live (30-39, female, Black Nigerian).

These narratives demonstrate how the strength of neighbourhood solidarity and belonging is rooted in an array of experiences shared cross-generationally, and include knowledge of the history and culture around local struggles and conflicts, particularly racism. Moreover, place stigma historically attached to Liverpool 8, particularly as regards safety and crime, and the barriers associated with such stigma, have seen residents responding with alternative narratives. Their emphasis on safety, diversity and pride in Liverpool 8 not only challenges and juxtaposes more powerful, mainstream and negative discourses, but act to reinforce residents' identity and belonging.

Allied to the theme of safety is residents' social construction of boundaries that transgress 'their' Liverpool 8. Residents identified locations where acceptance of diversity and 'safe boundaries' could be assumed, whilst other areas beyond Liverpool 8 were labelled 'no-go', particularly for BAME groups. The way such areas have been experienced has a long historical trajectory that persists amongst younger generations today. This might be explained in terms of local historical specificities, where historical Black settlement in Liverpool 8 led to hostility from surrounding White areas. In more recent years, racism and racist attacks have been increasing nationally, directed at immigrant groups, but also at long-established British born BAME communities. National debates on ethnic diversity and immigration, community cohesion and integration, the 'war on terror', national identity, and more recently Brexit, have 
informed hostile policy and public discourses that have fuelled tensions and in some senses normalised, and even legitimised, racial intolerance (Burnett, 2013; 2017).

Perceptions of social boundaries fall outside 'official' administrative boundaries such as postcodes or electoral wards, but represent significant defensive reactions to painful experiences of racism and fears around safety. This 'belonging through discrimination' emerged out of socio-economic and racial inequalities and subsequent hardships, whereby a sense of belonging can mitigate the negative effect of discrimination by offering a degree of emotional protection and resilience (see Yip, 2018 and Rivas-Drake et al., 2014 on ethnic and racial identity; Daley et al., 2018 on disability). Such adversity has strengthened pride of place and greater attachment to neighbourhood across generations.

Recent demographic and social changes might have an impact on the 'communities of memory' solidarities observed. The settlement of new migrant groups, alongside separate processes of gentrification, have presented challenges to some residents:

'[...] immigration is always a hot issue. A lot of non-English speakers have moved in [...] people are worried about the identity of Toxteth [...] I hear people who are the descendants of immigrants moaning or being threatened by immigration. It's hypocritical to me. [...] (18-29, Female, Black).

This mirrors the work of Phillips (2015) and others (Amin, 2006) in demonstrating how established communities may respond to newcomers with ambivalence and fear. Negotiating social change can be challenging, particularly where one's sense of national belonging is precarious (Phillips, 2015). However, the impact of new migration does not appear to have seriously disrupted neighbourhood solidarity, collective memory and the sense of pride and celebration around diversity, and others were more positive about these changes, positioning new migrant settlement as part of a longer historical trajectory: 'I think Toxteth has always been a place where immigrant families have come to. It's always been negotiated [...] where people become part of the community. [...] as has been the case for generations (18-29, Female, Black); 'I'm seeing a new Toxteth being born. [...] Toxteth is aesthetically getting better in terms of the mix of people [...] White Polish, .... Irish, ... Greek, White Muslims [...]' (4049, Male, Black). :

\section{Conclusions}


This paper has focussed on cross-generational belonging in an ethnically diverse working-class neighbourhood in south Liverpool. The findings from interviews with local residents contribute to our understanding of the complex processes involved in neighbourhood belonging, identity and inclusion. The wider literature around community, place, memory and neighbourhood belonging has informed our understanding of the issues and complexities involved in neighbourhood identity. This has helped identify similarities as well as differences between Liverpool 8 and other ethnically diverse working-class neighbourhoods. Similarities exist whereby portrayals of neighbourhood were 'bounded' into geographical borders that were not commensurate with socio-perceptual boundaries (see Massey, 1995: 54; Rogaly and Taylor, 2009). Interview respondents' definitions of Liverpool 8 were found to differ significantly from official administrative boundaries. This serves as an important reminder to neighbourhood researchers of the need to be sensitive when defining boundaries (see Catney et al 2018 for more on the methodological nuances of neighbourhood definitions), but this also has wider socio-policy implications. The results show how the 'everyday' geographies experienced and perceived by residents can be very different to those which are used to allocate resources (e.g., funding for deprived locales), or for electoral purposes. Alongside the similarities between working-class locales, unique neighbourhood-specific characteristics can be identified that have helped nurture, sustain and strengthen attachment and belonging in Liverpool 8. These in part rest on its long history of Black settlement that stretches back to at least the nineteenth century. The longevity and physical rootedness of the community have provided the basis upon which social mechanisms have shaped identity and added depth and meaning.

The findings demonstrate that, firstly, strong neighbourhood belonging and identity is transmitted between generations through narratives of past experiences of older generations. Secondly, shared contemporary experiences of class and racial disadvantage through continued social and economic marginalisation, policing and overt expressions of racism (verbal and physical attacks), serve to sustain and reinforce historically-based notions of belonging. This was common across older and younger generations, and between diverse ethnic/social groups. Shared experiences of inequalities in Liverpool 8 have cultivated strong social solidarity, articulated through cross-generational and widespread narratives around pride, safety, allegiance and affection for neighbourhood. This serves to challenge and contest 'common sensical' discourses and academic and policy research (e.g., Casey, 2016) that suggests diversity leads to conflict and lack of cohesiveness in communities (see Karner and Parker, 2011), as well as stand in sharp contrast to powerful mainstream accounts that stigmatise and 
undermine disadvantaged inner-city neighbourhoods like Liverpool 8 (and elsewhere). The strength of local empirical studies rests on the detail they provide in shining a light on how wider national and global processes play out at a micro-neighbourhood level.

Thirdly, our findings also reveal nuanced and subtle between-generation distinctions in some of the narratives. The interviews revealed a deeper politicised identity and attachment with Liverpool 8 amongst older generations; differences in the way younger generations observe and perceive changes relating to the diminishing stigma of Liverpool 8; and changes in the negotiation of space, seen in the beginnings of younger people's apparent and perceived greater spatial mobility and widening spatial horizons. This was expressed through accounts of social, educational and working lives that extend beyond neighbourhood to encompass city centre, suburban, and in some cases regional locations. Such changes relate to wider political processes in terms of the way global capitalism impacts on the local, particularly in the operation of familial and friendship networks. Changes in technologies of social and communication media may explain the more spatially-dispersed social interactions and experiences that undermine and dilute neighbourhood and place attachment, especially amongst younger generations (Savage et al., 2005).

Fourthly, whilst expanding spatial and social horizons weaken neighbourhood ties for some, the particularities of unequal power relationships at the intersections of 'race' and class can see global processes impacting locally in a plurality of ways. Disadvantaged socio-economic relationships can limit young peoples' spatial boundaries, where social networks outside the immediate community can be thwarted by enduring class and racial discrimination and placebased stigma. For example, while the expansion of UK Higher Education is associated with an increase in young people from disadvantaged backgrounds going to university, there are persistent inequalities in enrolment rates, rates of acceptance into prestigious institutions, educational attainment, and subsequent success in the labour market (Crawford et al., 2016). This can encourage greater reliance on familial and friendship networks at the neighbourhood level, so that local and community networks become stronger and more important as they represent significant relationships of support, belonging and identity (Warr, 2015). Community relationships appear, then, to be increasingly negotiated through the prism of both local and global exchanges (Clayton, 2011). Allied research on belonging and place illuminates how youth identities overlap with a myriad of life experiences (religious and cultural communities; youth cultures, virtual networks and social media), where practises of belonging 
locally are produced and reproduced through trans-local movement and influence (Condry, 2006). Such developments are imbued with issues of power and powerlessness. Some younger peoples' spatial horizons in Liverpool demonstrate continued constraint through experiences or fear of racism, and unease around defined 'no go' areas. Young people in Liverpool as elsewhere 'are seen to navigate landscapes of risk and opportunity' and draw on identities and resources from the local and the global 'within everyday contexts of relative powerlessness' (Clayton, 2011: 1689). Indeed, a hyper-awareness of the (perceived or actual) need to be vigilant in particular neighbourhoods outside Liverpool 8 represented a limitation to the increasing spatial mobility of young people, particularly those from BAME groups. Negotiations of 'safe' and 'unsafe' spaces, determined as such either by first-hand experience or through intergenerational transmission of local knowledge and perceptions, served to render particular locales persistently 'out of bounds'. Fears expressed on behalf of future generations' exposure to racism, which limited where participants were willing to move to with their children, suggests further intergenerational transmission of area perceptions in the future.

This research has been exploratory in terms of gauging levels of neighbourhood belonging and attachment at a time of unprecedented global social change. The paper demonstrates how the particularities of working-class neighbourhood identity, and the processes that shape it, are significant in providing important and alternative narratives that have either been silenced, delegitimised, or unheard. Positioning local narratives in broader structural processes is imperative if we are to make sense of these grassroots perspectives, as well as understand their significance for wider society. It is hoped that this micro-level neighbourhood study can shed light on some of the ways in which wider social changes are impacting locally, as well as to highlight issues that will stimulate further social enquiry.

\section{Footnote}

1. Gender here refers to social and cultural distinctions associated with being male or female and does not necessarily correspond to biologically-determined sex. 


\section{Acknowledgements}

We are indebted to all the participants who were generous with their time. Thanks to Leona Vaughn (Research Assistant) for undertaking the interviews and mental mapping and to the British Academy for their financial support for this work. Thank you to the anonymous reviewers for their constructive suggestions and support that have helped strengthen the paper.

\section{Funding}

This research was funded by the British Academy as part of the wider project 'The Role of People and Place in Neighbourhood Identity: Belonging and Social Inclusion' (Grant Reference: SG142055). 


\section{References}

Amin A (2006) The good city. Urban Studies 43 1009-23

Antonsich M (2010) Searching for belonging - An analytical framework. Geography Compass 4(6): 644-659.

Blokland T (2017) Community as Urban Practice. Cambridge: Polity.

Burnett J (2013) Racial Violence: Facing Reality London: Institute of Race Relations.

Burnett J (2017) Racial violence and the Brexit state. Race \& Class 58(4): 85-97.

Casey L (2016) The Casey Review: A Review into Opportunity and Integration. London: Department for Communities and Local Government.

Catney G et al (2018) Residents' perspectives on defining neighbourhood: mental mapping as a tool for participatory neighbourhood research Qualitative Research 1-18

Christian M (1995) Black Struggle for Historical Recognition in Liverpool. North West Labour History 20: 58-66.

Cole I (2013) Whose place? Whose history? Contrasting narratives and experiences of neighbourhood change and housing renewal. Housing, Theory and Society 30(1): 6583.

Condry I (2006) Hip-Hop Japan: Rap and the Paths of Cultural Globalization. Durham, NC: Duke University Press Books.

Costello R (2001) Black Liverpool: The Early History of Britain's Oldest Black Community, 1730-1918. Liverpool: Picton. 
Crawford C et al. (2016) Higher education, career opportunities, and intergenerational inequality. Oxford Review of Economic Policy 32(4): 553-575.

Daley et al. (2018) The social complexities of disability: Discrimination, belonging and life satisfaction among Canadian youth. Population Health 5: 55-63.

Devereux E et al. (2011) At the edge: Media constructions of a stigmatized Irish housing estate. Journal of Housing and the Built Environment 26(2): 123-142.

Donald B et al. (2014) Austerity in the city: economic crisis and urban service decline? Cambridge Journal of Regions, Economy and Society 7: 3-15.

Duffy S and Gillberg C (2018) Extreme Poverty in a Time of Austerity. Sheffield: Centre for Welfare Reform.

Foster D (2015) Assemble's Turner prize win: a sign of our deeply embedded housing crisis December. The Guardian, $8^{\text {th }}$ December, 2015.

Frost, D et al (2013). Militant Liverpool: a city on the edge. Liverpool: University of Liverpool Press

Frost D (2008) The Maligned, the despised and the ostracised: Working-class white women, inter-racial relationships and colonial ideologies in nineteenth and twentieth century Liverpool In: S. Haggerty, et al (eds). The Empire in One City? Liverpool's Inconvenient Imperial Past. Manchester, Manchester University Press

Frost D (1996) Racism and social segregation: settlement patterns of West African seamen in Liverpool since the nineteenth century New Community - The Journal of the European Research Centre on Migration and Ethnic Relations Volume 22 Number 1 January pp. 10. 
Gilroy P (1987) There Ain't No Black in the Union Jack: The Cultural Politics of Race and Nation London: Routledge.

Harris A (2014) Conviviality, conflict and distanciation in young people's local multicultures. Journal of Intercultural Studies 35(6): 571-587.

Hoelscher S and Alderman DH (2004) Memory and place: geographies of a critical relationship. Social and Cultural Geography 5(3): 347-355.

Hopkins P and Pain R (2007) Geographies of age: thinking relationally. Area 39(3): 287-294.

Jackson E and Benson M (2014) Neither “deepest, darkest Peckham” nor "run-of-the-mill" East Dulwich: The middle classes and their "others" in an inner-London neighbourhood. International Journal of Urban and Regional Research 38(4): 1195210.

Karner C and Parker D (2011) Conviviality and Conflict: Pluralism, Resilience and Hope in Inner-City Birmingham. Journal of Ethnic and Migration Studies 37(3): 355-372.

Liverpool City Council (2015) Ward Profiles. Available at: https://liverpool.gov.uk/council/key-statistics-and-data/ward-profiles/ (accessed 17 July 2019).

Massey D (1995) The conceptualization of place. In Massey D and Jess P (eds) A Place in the World?: Places, Cultures and Globalization. Oxford: Oxford University Press, pp. 4585.

May V and Muir S (2015) Everyday Belonging and Ageing: Place and Generational Change. Sociological Research Online 20(1): 8.

Mckenzie L (2015) Getting By: Estates, Class and Culture in Austerity Britain. Bristol: Policy Press.

Meegan et al. (2014) Global economic crisis, austerity and neoliberal urban governance in England. Cambridge Journal of Regions, Economy and Society 7: 137-153. 
Mitchell K and Elwood S (2013) Intergenerational Mapping and the Cultural Politics of Memory. Space and Polity 17(1): 33-52.

Moore R (2008) Reflections on community studies: from Sparkbrook to Liverpool. International Journal of Social Research Methodology 11(2): 121-127.

Murphy J (2011) Testimony of Merseyside Chief Constable interview with Frost (October 2010).

Neal S, Bennett K, Cochrane A and Mohan G (2019). Community and conviviality? Informal social life in multicultural places. Sociology 53(1): 69-86.

Phillips, D. (2015) Claiming spaces: British Muslim negotiations of urban citizenship in an era of new migration. Transactions of the Institute of British Geographers 40: 62-74

Putnam RD (2000) Bowling Alone: The Collapse and Revival of American Community. New York: Simon \& Schuster.

Rishbeth C and Powell M (2013) Place attachment and memory: landscapes of belonging as experienced post-migration, Landscape Research, 38(2): 160-178.

Rivas-Drake D, Syed M, Umaña-Taylor A, Markstrom C, French S and Schwartz, S. J. (2014) Feeling good, happy, and proud: A meta-analysis of positive ethnic-racial affect and adjustment. Child Development 85: 77-102

Rogaly B and Taylor B (2009) Moving Histories of Class and Community: Identity, Place and Belonging in Contemporary England. Basingstoke: Palgrave Macmillan.

Savage M and Bagnall G et al. (2005) Globalization and Belonging. London: Sage.

Shirlow P (2003) Ethnosectarianism and the reproduction of fear in Belfast. Capital \& Class 27(2): 77-93. 
Small S (1991) Racialised relations in Liverpool: A contemporary anomaly Journal of Ethnic and Migration Studies 17(4): 511-537.

Studdert D and Walkerdine V (2016) Being in community: re-visioning Sociology The Sociological Review 64: 613-621.

Tabili T (1996) Women "of a Very Low Type": Crossing racial boundaries in Late Imperial Britain. In Frader L and Rose S (eds) Gender and Class in Modern Europe Ithaca, New York: Cornell University Press, pp. 165-190.

Thompson P (2000) The Voice of the Past. Oxford: Oxford University Press.

Wacquant L (2008) The militarization of urban marginality: lessons from the Brazilian metropolis. International Political Sociology 2: 56-74.

Warr D (2015) The ambivalent implications of strong belonging for young people living in poor neighborhoods. In Wyn J and Cahill H (eds) Handbook of Children and Youth Studies Singapore: Springer Science \& Business Media.

Watt P (2006) Respectability, roughness and "race": Neighbourhood place images and the making of working-class social distinctions in London. International Journal of Urban and Regional Research 30(4): 776-797.

Wood N and Waite L (2011) Editorial: Scales of belonging. Emotion, Space and Society 4(4): 201-202.

Yip T (2018) Ethnic/racial identity—A double-edged sword? Associations with discrimination and psychological outcomes. Current Directions in Psychological Science 27(3): 170-175. 